\title{
PRODUCTION OF FOOD PRODUCTS IN EAST REGION: TRENDS AND FACTORS
}

\author{
D. Ruscheva* \\ Economic Research Institute at BAS, Sofia, Bulgaria
}

\begin{abstract}
The aim of the report is to highlight the scale of production of basic food products in the Southeastern Region of the Republic of Bulgaria. For its realization consistently exhibit characteristics of the region, output trends in the manufacture of food products, consider factors that affect its level and stand specialization, and place of the region in the formation of national food resources.
\end{abstract}

Key words: production of food products, areas, average yields, farm animals.

\section{INTRODUCTION}

The Southeastern region of Bulgaria is in the statistical area "North and South-east Bulgaria" and includes four districts: Bourgas, Sliven, Stara Zagora and Yambol. The idea of the report is to assess the position of the region in the formation of national food resources. Its realization is related to the analysis of parameters, trends and specialization of the region in terms of production of basic food products. In selecting them, the assumption is that they are important for agriculture and food industry and participate in feeding Bulgarians. Subject are 23 products, of which agriculture are 17: crops (wheat, barley, grain maize), sunflower, beans, potatoes, vegetables (tomatoes, peppers), fruit (apples, plums, cherries, apricots and peaches) and grapes (wine and table), milk and eggs from the food industry 6: red meat, milk, yogurt, cheese and yellow cheese.

\section{Characteristics of the area.} The characteristics of the region refer to the population as a creator and consumer of products and to the territory and its balance sheet as opportunities for agricultural production.

\section{Population}

Numbers. The population of the Southeast region to 31.12 .2012 was 1067.9 thousand people [1]. Compared to 2008 [2] it decreased by 53,7 thousand people, but its share of the

$$
\text { Darina }{ }^{*}
$$

Correspondence to: Ruscheva, Economic Research Institute at BAS, tel. +3598965398 66, e-mail: darinar@abv.bg,Sofia 1000,Aksakov Str.3 total population of Bulgaria is preserved $14.7 \%$.

Density. It declined from 56.8 people per square kilometer (2008) 53.9 (2012) and is slightly lower than the average population density of the country. Settlements. In 2012, in the Southeast region has 681 settlements, including 41 towns and 640 villages.

Population structure according to labor age. In 2012, the population structure is as follows: under labor age $-15.9 \%$, of labor age $-60.9 \%$ and over labor age $-23.2 \%$. In the Southeast region, compared to Bulgaria (23.3\%) is worse indicators of population under labor age (15.9\%). Regarding the 2008 change in the direction of reducing the population in and labor age population growth over labor age. The ratio of percentage of the unemployment in the Southeast region ranged from 5.8\% (2008) to $11.9 \%$ (2012) and about the same as the values of this indicator for the country.

Relative share of food costs and beverages in consumer spending. In 2011, [3] it was 34, and $2 \%$ is slightly lower than the average for Bulgaria - $36.2 \%$.

\section{Territory}

Balance of the territory. In 2010, [4] the territory of the South-East region is 19.8 million. Decrees, of which agricultural land is $11.3(57,1 \%)$. Cultivated land has $80.0 \%$ of the agricultural land and irrigated areas $-13.2 \%$ of cultivated land. In 2010, Southeastern region has $17.7 \%$ of the agricultural land, $18.3 \%$ of the 
cultivated and $16.2 \%$ - from irrigated areas of Bulgaria.

Structure of agricultural areas. In 2012, in the Southeast region structure of agricultural areas is: crops - $57.1 \%$, oilseed crops - $34.8 \%$, industrial crops $-6.3 \%$, vegetable crops $-0.1 \%$ and grassland and annuals fodder - 1, 7\%. Compared with this structure in Bulgaria and South-East region has the highest proportion of crops and differences is several times higher share of industrial crops at the expense of the lower share of vegetable crops and grassland and annual feed cultures.

In the context of the idea of the report can be summarized that the Southeast region of Bulgaria on many of the indicators considered is similar to the national average values. Trends in population in the region are decreasing, including the population under labor age and aging, they mostly live in villages. This means that in perspective it can be expected to decrease the population as a potential producer, to increase user for food products, which can create tension and to create difficulties on the production and consumption of food products. In terms of the structure of agricultural areas compared to Bulgaria Southeast region has expressed specialization to crops and oilseeds.

\section{Dimensions and trends in the production of basic food products.}

Crops. In 2012, in the Southeast region is produced wheat - 866.4 thousand tons, barley 224, 9 thousand tons and corn for grain - 36.3 thousand tons [1]. An increase in wheat production compared to 2002 with 53.8 percent, while barley production decreased in 2012 and reached $80.0 \%$ of its level in 2002. In comparison to these two crops, maize production is considerably less in 2012 and decreased $90,5 \%$ of that in 2010 .

Sunflower. Typical for South-East region of Bulgaria is that in terms of sunflower production in 2012 from 221.1 thousand tons was about 4 times higher compared to 2002 .

Beans. In the Southeast region of production is small beans - just 85 tons in 2012. Although small the quantities have almost half of production in 2002 .

Potatoes. In 2012, the region produced 7.9 thousand tons of potatoes, which represents $26 \%$ of the amount produced in 2002. Vegetable crops. Tomato production in the region in 2012 was 6.9 thousand tons, and pepper - 3.6 thousand tons. These quantities are respectively $12.8 \%$ and $46,2 \%$ of the produced quantities of tomatoes and peppers in the region in 2002.

Fruits. In 2012, in the Southeast region are produced peaches - 15.5 thousand tons, cherries - 10.6 thousand tons, apples - 6.3 thousand tons, plums - 4.2 thousand tons and apricots - 0 , 556 thousand tons. Compared to 2002, production increased more than six times of plums and cherries and more than 3 times of apples. Increases production of peaches by $14 \%$ compared to the 2010 year. Only reduces the production of apricots by 18 percentage points. Grapes. In 2012, dimension of production of grapes in the region is wine grapes - 106, 9 thousand tons and table grapes - 1.7 thousand tons. While in the wine grapes production increased by 23.9 percent, production of table grapes - reduces and is about $37 \%$ of the level in 2002

Milk production (agriculture). In 2012, the region produced 224, 8 million liters of milk, which is about 8 percentage points less compared to 2010. The structure by type of milk is as follows: cow's milk - $89.4 \%$, sheep's milk $-6.5 \%$ goat milk $-3.5 \%$ and buffalo milk $-0.6 \%$.

Eggs. Egg production in the region in 2012 is EUR 3176 million units. It also reduced and $73.6 \%$ compared to 2010 .

Production of red meat. In the Southeast region were produced in 2011, 3.8 thousand tons of red meats. In the previous year the production of this product increased slightly, with 90 tons. Milk. The production of milk in 2011 was 3 million. Liters, which is $61 \%$ of the level achieved during the previous 2010 years.

Yoghurt. In 2011 they produced 15, 9 thousand tons yogurt. Compared with 2010, it is about 9 percentage points lower.

Milk fat. In 2011, the region produced 115 tons of milk fats, which are $64 \%$ more in relation to the previous year.

White brined cheese. In the region in 2011 produced 2800 tons white brined cheese by $55 \%$ more than in 2010.

Yellow cheese. In 2011, the region produced 7600 tons of cheese, which amounts are almost equal to those produced in 2010.

The summary, which can be done, is that of 23 observed product in 8 (sunflower, wheat, apples, plums, cherries, peaches, grapes and milk) production in the region is increasing. Quickly this process occurs in sunflower and wine grapes. In fruit also increased 
significantly, but in this case it comes to production in smaller quantities. Almost does not change the production of cheese. In other food products $14 \quad(60.8 \%)$ production decreased. This group includes important to feed the population products - beans, tomatoes, milk, eggs, and cheese. There is a similar picture at national level in terms of reducing the production of basic food products. And the consequences of these processes at both national and regional levels are associated with decreased resources of basic food products intended for processing, marketing and export. It got to the emergence of food deficits, which are covered by imports and domestic production farms of the population.

\section{The main factors limiting the production of food products.}

Along with the quantitative and qualitative characteristics of the population and the balance within the Southeast region of Bulgaria for the production of crops and livestock products are important, areas and farm animals. Areas. In 2012, [1] in the Southeastern region of Bulgaria have grown crops on these areas: wheat - 240.2 thousand hectares, barley - 67.3 thousand hectares, corn for grain - 13.9 thousand hectares, sunflower - 149.5 thousand hectares, beans - 0.109 thousand hectares, potatoes - 0,496 thousand hectares, tomatoes 0.457 thousand hectares, pepper - 0.226 thousand hectares, apples - 0,718 thousand hectares, plums - 0,966 thousand hectares cherries - 3.3 thousand hectares, apricots 0,137 thousand hectares, peaches - 2.2 thousand hectares of wine grapes - 20.4 thousand hectares and table grapes - 0.545 thousand hectares Compared to 2010 [4] the changes in the area are as follows:

- Crops (5), whose areas increase, arranged in ascending order: wheat $(1.8 \%)$, sunflower (by $14.0 \%)$, wine grapes (20.0 percent), grain maize (with 36.3\%) and apricots (52.2\%); - Crops (9), whose areas decrease, in descending order: barley $(98.4 \%)$, cherries (94.3\%), tomatoes $(92.7 \%)$, plums $(90.3 \%)$, beans $(80,7 \%)$, apples $(74.6 \%)$, table grapes $(68.1 \%)$, potatoes $(55.1 \%)$ and pepper $(46.8 \%)$;

- Peaches (1), the amount of land remains unchanged for those years. Just three years in $9(60 \%)$ of the observed crop areas in the region decreased. This is especially sharp in pepper, potatoes and table grapes.

Relation between changes in production and the size of the areas. In 2012 compared with 2010 in the Southwest region outlines two extreme groups crops in terms of that relationship:
- Crops in which the production areas and increased: wheat and wine grapes; - Crops where production and reduce their areas: beans, tomatoes, peppers, potatoes, apples, plums, cherries and table grapes.

We can summarize that the reduction in production of crops in almost half is the result of reduction of their areas. Average yields. In 2012, in the Southeast region of Bulgaria according to the level of average yields crops conditionally can be grouped into the following groups:

- Crops, where average yields in the region are higher than those for the country: potatoes, apples, plums, cherries, apricots, peaches and wine grapes; - Crops, where average yields in the region are lower than those for the country: grain maize, beans, tomatoes and table grapes.

Livestock. In 2012, [1] in the Southeastern region of Bulgaria are grown: cattle - 94,7 thousand units, buffaloes - 1.9 thousand units, sheep - 249.5 thousand units, pigs - 146.1 thousand units and poultry -2.1 million units In the same year the proportion of the types of livestock and poultry, which are grown in the region in comparison with the total number in the country is as follows: cattle - $18.0 \%$, buffalo $-20.6 \%$, sheep $-18,3 \%$, goats $-15.3 \%$ and poultry $-13.7 \%$.

Compared to 2010 [4] most types of livestock decreased, in descending order sheep (85.9\%), cattle $(84.4 \%)$, poultry $(84.0 \%)$ and goats $(67$. $2 \%$ ). Marginally increased by $6 \%$ of the number of buffaloes and more tangible - the pigs by $12.5 \%$. Therefore reducing production of milk and eggs should be mainly associated with reducing the number of livestock and poultry in the region.

\section{Specialization and place the region in the formation of national food resources.}

The Southeastern region in Bulgaria mainly specializes in the production of crops, oilseeds, peaches and wine grapes. It has favorable soil and climatic conditions and experience in their manufacture. Limited to the areas and production of beans, potatoes, vegetable crops (tomatoes, peppers), some fruits (apples, plums, cherries) and table grapes. Cow's milk accounts for about $90 \%$ of total production in the area.

The location of the Southeast region of Bulgaria in the formulation of national food resources is determined by the relative share of the basic food goods in the total country production. For 2012 investigational products grouped and sorted in ascending order on this indicator look like this: 
- Up to $10 \%$ (of the total country production) six crops: corn grain $(2.1 \%)$, potatoes $(5.2 \%)$, beans $(5.3 \%)$, apricots $(5.4 \%)$, tomatoes $(7.3 \%)$ and pepper (7.6\%); - 11-20\%, 6 (crops and livestock products), eggs (15.0\%), sunflower (15.9\%), plums $(18.3 \%)$, milk (18.7\%) wheat (19.4\%) and table grapes (19.8 percent); - $11-30 \%$ of apples (21 4\%); - $31-40 \%$ of barley (34.0\%); - $41-50 \%, \quad$ grapes $(42.7 \%)$; - 51-60\%, cherries (54.4\%); - 61-70\%, peaches $(61.5 \%)$.

In 2011 the share of certain products from the food industry: fresh milk $(4.5 \%)$, cheese $(6.3 \%)$, production of red meat $(6.8 \%)$, milk fat $(10.2 \%)$, yogurt $(13.5 \%)$ and yellow cheese $(39.0 \%)$.

\section{CONCLUSIONS}

1. With many indicators Southeast region of Bulgaria is approaching the national average. 2. The population of the region and reduces aging, which generated further problems in terms of quantitative and qualitative parameters of the labor force and consumers of food products.

\section{RUSCHEVA D.}

3. Restructuring of areas occupied by crops is expressed in increasing the size of wheat and wine grapes. For most crops, providing products to feed the population areas be reduced and this in turn determines the boundaries of the changes in quantity production.

4. In the majority of food products in the production area decreases, this causes food deficits.

5. Southeastern region of Bulgaria has an important place in the formation of national food resources. It is reflected in the high share of national production of peaches, cherries, grapes, barley and yellow cheese, which provides Southeast region.

\section{REFERENCES}

1. Regions, Districts and Municipalities in Republic of Bulgaria 2012, NSI, S., 2014.

2. Regions, Districts and Municipalities in Republic of Bulgaria 2008, NSI, S., 2010.

3. Regions, Districts and Municipalities in Republic of Bulgaria 2011, NSI, S., 2013.

4. Regions, Districts and Municipalities in Republic of Bulgaria 2010, NSI, S., 2012. 